\title{
1 Investigating sources and pathways of 2 perfluoroalkyl acids (PFAAs) in aquifers in Tokyo 3 using multiple tracers
}

4 Keisuke $\operatorname{Kuroda}^{\mathrm{a} * 1}$, Michio Murakami ${ }^{\mathrm{b}}$, Kumiko Oguma ${ }^{\mathrm{a}}$, Hideshige Takada ${ }^{\mathrm{c}}$, and Satoshi

$5 \quad$ Takizawa $^{\mathrm{a}}$

6 a Department of Urban Engineering, Graduate School of Engineering, The University of

7 Tokyo, 7-3-1 Hongo, Bunkyo, Tokyo, 113-8656, Japan

8 b Institute of Industrial Science, The University of Tokyo, 4-6-1 Komaba, Meguro, Tokyo, 9 153-8505, Japan

10 c Laboratory of Organic Geochemistry (LOG), Institute of Symbiotic Science and 11 Technology, Tokyo University of Agriculture and Technology, Fuchu, Tokyo 183-8509, 12 Japan

13 * Corresponding author: 16-2 Onogawa, Tsukuba, Ibaraki, 305-8506 Japan, 14 keisukekr@gmail.com, Phone: +81298502843,Fax: +81298502920

151 Present address: Center for Environmental Risk Research, National Institute for 16 Environmental Studies (NIES), 16-2 Onogawa, Tsukuba, Ibaraki, 305-8506 Japan

\section{Abstract}

18 We employed a multi-tracer approach to investigate sources and pathways of perfluoroalkyl

19 acids (PFAAs) in urban groundwater, based on 53 groundwater samples taken from confined

20 aquifers and unconfined aquifers in Tokyo. While the median concentrations of groundwater 
21 PFAAs were several ng/L, the maximum concentrations of perfluorooctane sulfonate (PFOS, $22990 \mathrm{ng} / \mathrm{L}$ ), perfluorooctanoate (PFOA, $1800 \mathrm{ng} / \mathrm{L}$ ) and perfluorononanoate (PFNA, 620 ng/L)

23 in groundwater were several times higher than those of wastewater and street runoff reported 24 in the literature. PFAAs were more frequently detected than sewage tracers (carbamazepine 25 and crotamiton), presumably owing to the higher persistence of PFAAs, the multiple sources 26 of PFAAs beyond sewage (e.g., surface runoff, point sources) and the formation of PFAAs 27 from their precursors. Use of multiple methods of source apportionment including principal 28 component analysis-multiple linear regression (PCA-MLR) and perfluoroalkyl carboxyl acid 29 ratio analysis highlighted sewage and point sources as the primary sources of PFAAs in the 30 most severely polluted groundwater samples, with street runoff being a minor source $(44.6 \%$ 31 sewage, $45.7 \%$ point sources and $9.7 \%$ street runoff, by PCA-MLR). Tritium analysis

32 indicated that, while young groundwater (recharged during or after the 1970s, when PFAAs 33 were already in commercial use) in shallow aquifers ( $<50 \mathrm{~m}$ depth) was naturally highly 34 vulnerable to PFAA pollution, PFAAs were also found in old groundwater (recharged before 35 the 1950s, when PFAAs were not in use) in deep aquifers (50-500 m depth). This study 36 demonstrated the utility of multiple uses of tracers (pharmaceuticals and personal care 37 products; PPCPs, tritium) and source apportionment methods in investigating sources and 38 pathways of PFAAs in multiple aquifer systems.

39 Keywords

40 perfluoroalkyl acids (PFAAs); groundwater; pharmaceuticals and personal care products 41 (PPCPs); tritium; sewage; source apportionment

\section{Abbreviations}

43 PFAAs, perfluoroalkyl acids; PFSAs, perfluorinated sulfonic acids; PFCAs, perfluoroalkyl 
44 carboxylic acids; PFHxS, PFHpS, PFOS, PFDS, PFHpA, PFOA, PFNA, PFDA, PFUnDA, 45 PFDoDA, PFTrDA and PFTeDA; PFAA abbreviations, see Section 2.3; FOSA, 46 perfluorooctane sulfonamide; AFFF, aqueous film-forming foams; PCA, principal component 47 analysis; PC, principal component; MLR, multiple linear regression; FS, PCA factor score; 48 PFCAR, perfluoroalkyl carboxyl acid ratio analysis; L-PFCAR, long/(long + short) PFCAR; E-PFCAR, even/(even + odd) PFCAR; PPCPs, pharmaceuticals and personal care products;

50 TU, tritium unit; BGL, below ground level

\section{1. Introduction}

52 Perfluoroalkyl acids (PFAAs) are a group of compounds which have $\mathrm{C}_{n} \mathrm{~F}_{2 n+1}-\mathrm{R}$ structure, 53 where $\mathrm{R}$ is carboxyl, sulfonic, sulfinic, phosphonic or phosphinic functional group (Buck et 54 al., 2011). PFAAs have been broadly used as surfactants for various industrial and consumer 55 products since the 1950 s, because they are resistant to thermal, physical, chemical and metabolic degradation owing to their strong carbon-fluorine bonds (Kissa, 2001). Due to their water-soluble and persistent nature, PFAAs have been ubiquitously detected in various water environments, including surface water (Huset et al., 2008; Murakami et al., 2008a; Nakayama et al., 2010; Zushi et al., 2011), rainwater (Kim and Kannan, 2007; Scott et al., 2006), drinking water (Mak et al., 2009; Quiñones and Snyder, 2009), wastewater (Huset et al.,

61 2008; Schultz et al., 2006; Sinclair and Kannan, 2006), and sediments (Higgins et al., 2005;

62 Sakurai et al., 2010; Zushi et al., 2010). The potential environmental and toxicological impact 63 of PFAAs has been a growing concern, for especially "long-chain" perfluorinated sulfonic 64 acids $\left(\mathrm{C}_{\mathrm{n}} \mathrm{F}_{2 \mathrm{n}+1} \mathrm{SO}_{3} \mathrm{H}, \mathrm{n} \geq 6\right.$, PFSAs $)$ and perfluoroalkyl carboxylic acids $\left(\mathrm{C}_{\mathrm{n}} \mathrm{F}_{2 \mathrm{n}+1} \mathrm{COOH}, \mathrm{n} \geq 7\right.$, 65 PFCAs) and their corresponding anions (OECD, 2011; USEPA, 2009), which have been 66 shown to be more bioaccumulative than their short-chain analogues (Conder et al., 2008; 
Olsen et al., 2009).

Generally, PFAA pollution is more intense in urban areas than in remote areas, because of the presence of major PFAA sources, including wastewater treatment plants (WWTPs) (Schultz et al., 2006; Sinclair and Kannan, 2006) and nonpoint sources such as surface runoff (Houtz and Sedlak, 2012; Kim and Kannan, 2007; Murakami et al., 2009b; Nguyen et al., 2011; Xiao et al., 2012; Zushi and Masunaga, 2009; Zushi et al., 2008). In groundwater, extremely high levels of PFAAs ( $\mu \mathrm{g} / \mathrm{L}$ to $\mathrm{mg} / \mathrm{L}$ level) have been found in fire training areas, owing to the use of aqueous film-forming foams (AFFF) (Houtz et al., 2013; Moody and Field, 1999; Schultz et al., 2004; Weiß et al., 2012). In other areas, groundwater studies have mainly focused on assessing the impact of PFAAs on humans (Jin et al., 2009; Post et al., 2009; Quiñones and Snyder, 2009) and wildlife (Plumlee et al., 2008) based on the detected PFAA concentrations. These latter studies showed that, although PFAA levels in groundwater in general were not currently alarming, concentrations in groundwater impacted by anthropogenic activities (e.g., WWTP effluents or industries) were close to levels that can produce adverse effects on human 81 health and the environment (Plumlee et al., 2008; Post et al., 2009). Therefore, in-depth 82 studies are required on source identification and apportionment of groundwater PFAAs having multiple potential sources and on pathways of those PFAAs in the subsurface. In

84 groundwater, various factors, such as adsorption and production from precursors (Higgins and Luthy, 2006; Murakami et al., 2009a), would be involved in PFAA occurrence during 86 long-term subsurface passage. However, PFAA distribution in aquifers and pollution 87 pathways has only been studied in detail in a coastal dune of the Rhine River (Eschauzier et 88 al., 2010), and the apportionment of multiple sources of groundwater PFAAs has only been 89 attempted in our previous study, examining 16 samples mostly from shallow unconfined 
90 aquifers in Tokyo (Murakami et al., 2009a). The vertical and horizontal distribution, pollution

91 pathways, and source identification and apportionment of PFAAs, within complex aquifer 92 systems, have not yet been studied.

93 Tracers are useful in analyzing groundwater hydrology and pollution. Tritium $\left({ }^{3} \mathrm{H}\right)$ is a 94 suitable hydrological tracer because it is a constituent of the water molecule. Using tritium, 95 young groundwater recharged after the 1950s-1960s can be differentiated from older 96 groundwater. Considering that PFAA mass production began in the $1950 \mathrm{~s}$, tritium can be a 97 useful tracer for identifying pathways of PFAAs in groundwater. Pharmaceuticals and 98 personal care products (PPCPs) are useful tracers of sewage in groundwater (Kuroda et al., 99 2012; Nakada et al., 2008), and have been applied as sewage tracers to investigate PFAA 100 sources in surface and marine waters (Murakami et al., 2008a; Murakami et al., 2011), but not 101 yet in groundwater.

102 Regarding methods of PFAA source identification and apportionment in groundwater, PFCA 103 ratio analysis (PFCAR) (Nguyen et al., 2011; Simcik and Dorweiler, 2005), and statistical 104 approaches such as principal component analysis (PCA) and multiple linear regression (MLR) 105 (Furl et al., 2011; Murakami et al., 2011; Nguyen et al., 2011), are easy to apply, since they 106 do not require quantification of groundwater flow. Our previous study on Tokyo groundwater 107 demonstrated a PFAA source apportionment method using PFCAR, assuming that sewage 108 and street runoff were the major sources (Murakami et al., 2009a). The source apportionment 109 method, however, has been applied only to a limited amount of data, and hence must be 110 verified by other methods (e.g., statistical approaches) and with other data (e.g., sewage-tracer 111 PPCPs).

112 The aim of this study is to investigate the sources and pathways of city-wide groundwater 
113 pollution by PFAAs in multiple aquifers in central Tokyo, using a multi-tracer approach and

114 multiple methods of source apportionment. We examined 53 samples of groundwater from

115 shallow to deep ( $<500 \mathrm{~m}$ depth) aquifers, and 5 samples of tap water. The occurrence of

116 PFAAs in groundwater was compared with that of PPCPs measured in our parallel study

117 (Kuroda et al., 2012), to investigate the sources and fate of PFAAs in the subsurface. In order

118 to identify PFAA sources and their contribution to PFAAs in groundwater, PCA followed by

119 MLR (PCA-MLR), and PFCAR, were applied. The source apportionment results using

120 PCA-MLR and PFCAR were further verified by the reported concentrations of PPCPs and

121 heavy metals in the same samples (Kuroda, 2010; Kuroda et al., 2012) and those of PFAAs

122 and PPCPs in river water, wastewater, and street runoff samples in the region (Morimoto et

123 al., 2011; Murakami et al., 2008a; Murakami et al., 2009b; Zushi et al., 2011). Then, the

124 mechanisms and pathways of PFAA pollution in the aquifers were investigated using tritium

125 analysis, together with data on aquifer depths and hydrogeological conditions. Finally, the

126 utility of these tracers and source apportionment methods was evaluated.

127 2. Materials and methods

$128 \quad$ 2.1. Site description

$129 \quad 2.1 .1$ Study area and geology

130 Figure 1 shows the study area, central Tokyo, with surface geology (Tokyo Metropolitan

131 Government, 2001). The study area's location and geological cross-sections (Tokyo Institute

132 of Civil Engineering and Technology Research, 1996) are shown in Figure S1

133 (Supplementary Information: hereafter, SI). The geology and the groundwater flow are

134 described elsewhere (Kuroda et al., 2012); briefly, Tokyo's geology is characterized by the

135 loam-covered Pleistocene Musashino Terrace in the west and the alluvium-covered Holocene 
136 Tokyo Lowland in the east (Endo, 1992; Tokyo Metropolitan Government, 2006). In the

137 Terrace, the major unconfined aquifer is the gravel layer at 5-20 m below ground level

138 (BGL). In the Lowland, the unconfined aquifer is the Yurakucho Layer at 0-40 m BGL.

139 Beneath these unconfined aquifers, the Pleistocene Tokyo Layers, alternating layers of silt, 140 sand and gravel, form a middle zone, between the Terrace and the Lowland, at 0-50 m BGL.

141 The Plio-Pleistocene Kazusa Layers, consisting of alternating layers of sand, gravel and silt, 142 are the lowermost ( $>30 \mathrm{~m}$ BGL) confined aquifers, lying beneath both the Terrace and the 143 Lowland (Tokyo Institute of Civil Engineering and Technology Research, 1977).

$144 \quad 2.1 .2$ Groundwater recharge

145 The unconfined aquifers are mainly recharged by rainwater infiltration $(123 \mathrm{~mm} / \mathrm{year})$ and 146 leakage from water mains (91 mm/year) (Watanabe et al., 2009). Unconfined groundwater

147 flows into rivers (Tokyo Institute of Civil Engineering and Technology Research, 1977).

148 Rainwater infiltration is small in the study area because of little permeable surface. As of

1492006 , the major land uses are housing and buildings (60\%) and streets (23\%), which have low 150 permeability, and highly permeable land surfaces are minor (parks $6.6 \%$, agricultural land $151 \quad 1.2 \%$, bare land $0.9 \%$ and forest $0.1 \%$ ) (Bureau of Urban Development, Tokyo Metropolitan

152 Government). Exfiltration of sewage from leaky sewer pipes could be an additional source of 153 recharge (19-38 mm/year) (Kuroda et al., 2012). The exfiltration was considered the main 154 pathway of sewage into Tokyo's subsurface, based on PPCP detection (Kuroda et al., 2012; 155 Nakada et al., 2008). Large-scale infiltration of untreated or treated wastewater by artificial 156 aquifer recharge, bank filtration, or on-site sewage disposal, is not an issue, except for the 157 natural recharge from the two small canals (the Senkawa Josui Canal and the Tamagawa Josui 158 Canal; Figure 1) running through the elevated part of the Terrace, in which reclaimed 
159 wastewater has been introduced. However, the elevated PPCP levels were not observed in the

160 canals' vicinity and PPCPs were detected widely in the region (Kuroda et al., 2012). The

161 residence time of the confined groundwater in Tokyo, at depths of 40-124 m BGL, was

162 estimated to be 11-28 years, using tritium analysis (Imaizumi et al., 2000). This relatively

163 short residence time, relative to the depth, can be explained by the geology (see Figure S1);

164 the Tokyo Layers' aquifers are partially connected with the upper unconfined aquifers

165 because of intermittent silt layers, allowing for recharge from the unconfined aquifers. The

166 Kazusa Layers of $<100 \mathrm{~m}$ depth are considered to be recharged within just a few kilometers

167 from both the upper unconfined aquifers and the Tokyo Layers, because the alternating layers

168 of the Kazusa Layers are in contact with those upper aquifers due to the Kazusa Layers' dip

169 of approximately one degree from west to east, and from south to north ((Tokyo Institute of

170 Civil Engineering and Technology Research, 1996) and Figure S1).

\section{$171 \quad$ 2.2. Sampling locations}

172 For PFAA analysis, we collected 53 groundwater and 5 tap water samples (Figure 1), between

173 October 2007 and October 2009. Of the groundwater samples, 32 originated from unconfined

174 aquifers (10-30 m BGL), 3 from springs (flowing from ambient unconfined aquifers), and 18

175 from confined aquifers (20-500 m BGL). The non-spring groundwater samples were taken

176 from existing wells for emergency use, public baths and drinking water. The method for

177 identifying sampled aquifers is described in S1 (SI), and the basic information on the

178 groundwater samples is shown in Table S1 (SI). PFAAs in 8 of the 53 sites investigated in

179 this study had been measured in 2006 (Murakami et al., 2009a). The major source of Tokyo's

180 water supply is river water that is typically treated by flocculation, sedimentation and sand

181 filtration. Ozonation and granular activated carbon are also employed to treat a part of the 
total supply volume (Bureau of Waterworks, Tokyo Metropolitan Government). Tritium

183 levels were analyzed in 15 of the 53 groundwater samples. At 7 locations, both tritium and

184 PFAA samples were simultaneously taken; and the other 8 tritium samples were separately

185 taken in 2009.

186 2.3. Sampling and analysis of PFAAs and FOSA

187 We analyzed four PFSAs and eight PFCAs: perfluorohexane sulfonate (PFHxS), 188 perfluoroheptane sulfonate (PFHpS), perfluorooctane sulfonate (PFOS), perfluorodecane

189 sulfonate (PFDS), perfluoroheptanoate (PFHpA), perfluorooctanoate (PFOA), 190 perfluorononanoate (PFNA), perfluorodecanoate (PFDA), perfluoroundecanoate (PFUnDA),

191 perfluorododecanoate (PFDoDA), perfluorotridecanoate (PFTrDA) and 192 perfluorotetradecanoate (PFTeDA). Perfluorooctane sulfonamide (FOSA), which is 193 considered a precursor of PFAAs (Prevedouros et al., 2005), was also measured. The details 194 of sampling, analytical methods, and chemical used are given elsewhere (Murakami et al., 195 2008a; Nishikoori et al., 2011). Briefly, the collected sample waters were filtered through 196 pre-baked glass-fiber filters (GF/F, pore size: $0.7 \mu \mathrm{m}$; Whatman) and stored at $5{ }^{\circ} \mathrm{C}$ until 197 analysis. PFAAs and FOSA in the $0.7 \mu \mathrm{m}$-filtrate $(1000 \mathrm{~mL})$ were concentrated by 198 solid-phase extraction (SPE); after filtration, ${ }^{13} \mathrm{C}$-labeled $\mathrm{PFOS},{ }^{13} \mathrm{C}$-labeled PFOA and

$199{ }^{13} \mathrm{C}$-labeled PFDA were spiked into aliquots of samples, and then the samples were passed 200 through Sep-Pak Plus tC18 cartridges (Waters) preconditioned with $20 \mathrm{~mL}$ methanol and then $20110 \mathrm{~mL}$ distilled water. A flow rate of $<10 \mathrm{~mL} / \mathrm{min}$ was maintained. The cartridges were

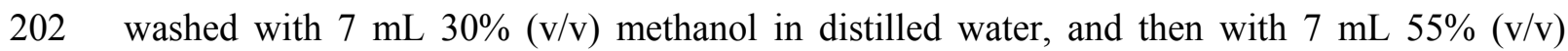
203 methanol in distilled water that was acidified with $4 \mathrm{M} \mathrm{HCl}$ to $\mathrm{pH}$ 2.0-2.5. The target 204 compounds were eluted with $20 \mathrm{~mL}$ methanol. The samples had a good diffusion within 
methanol. The eluate was concentrated to $500 \mu \mathrm{L}$, and PFAAs and FOSA in the methanol

206 were analyzed by liquid chromatography-tandem mass spectrometry (LC-MS/MS: Agilent

2071100 and TSQ Quantum) with a Zorbax Rx-C8 column (Agilent) in electrospray negative

208 ionization mode. A gradient mobile phase of $0.5 \mathrm{mM}$ ammonium acetate in distilled water 209 and $0.5 \mathrm{mM}$ ammonium acetate in acetonitrile was used. At a flow rate of $0.3 \mathrm{~mL} / \mathrm{min}$, the 210 mobile phase gradient was ramped from $20 \%$ to $100 \% 0.5 \mathrm{mM}$ ammonium acetate in 211 acetonitrile in $5 \mathrm{~min}$, maintained at $100 \%$ for $11 \mathrm{~min}$, and then ramped down again to $20 \%$.

212 The capillary temperature was maintained at $350{ }^{\circ} \mathrm{C}$. Ions were monitored in selected reaction 213 monitoring mode. Monitored parent and product ions are listed in Table S2. PFHxS, PFHpS

214 and PFOS were recovery-corrected with ${ }^{13} \mathrm{C}$-PFOS. PFHpA, PFOA and PFNA were 215 recovery-corrected with ${ }^{13} \mathrm{C}_{2}$-PFOA. PFDA, PFUnDA, PFDoDA, PFTrDA and PFTeDA were

216 recovery-corrected with ${ }^{13} \mathrm{C}$-PFDA. PFDS and FOSA were not recovery-corrected; this was

217 because their concentrations without recovery-correction using ${ }^{13} \mathrm{C}$-compounds showed better 218 reproducibility and recovery than the case with recovery-correction.

219 With every batch of samples (usually five), distilled water was brought to the field and 220 analyzed as a travel blank. The LOQs (limits of quantification) were set at the larger values of 221 either three times of the travel blank concentrations or the lowest calibration standard, and 222 were $0.25-3.7 \mathrm{ng} / \mathrm{L}$.

\section{2.4. Sampling and analysis of tritium}

224 Tritium was measured using a low-background liquid scintillation counter (LSC-LB5, Hitachi

225 Aloka Medical, Ltd.) following electrolytic enrichment of tritium by a factor of about 25 226 using Fe-Ni electrodes. The LOQs were 0.2-0.3 tritium unit (TU), and relative standard 227 deviation of samples was within $\pm 5 \%$. The tritium measurements were conducted at 
Geo-Science Laboratory Co. Ltd., Nagoya, Japan.

229

230

231

232

233

234

235

236

237

238

239

240

241

242

243

244

245

246

247

248

249

250

\subsection{Quality control and quality assurance of PFAAs and FOSA}

The reproducibility and recovery tests were performed in this study for quality control and assurance by using WWTP effluent ( $n=4$; Tables S3 and S4). Relative standard deviation (RSD) were less than 23\%, while that of PFDS, PFHpA and PFUnDA ranged 29-43\%, probably due to large experimental errors associated with low concentrations $(0.8-5.3 \mathrm{ng} / \mathrm{L})$. Indeed, RSD in PFAA-spiked WWTP effluent were only less than 14\% except for PFTeDA (21\%). The recovery rates of PFAAs spiked into the WWTP effluent were within $100 \pm 15 \%$ for majority of PFAAs and for FOSA. The recovery rates of PFHxS were higher (128\%) and those of PFUnDA (74\%) were lower, perhaps due to the difference in magnitude of ionization from labeled surrogate compounds. Regarding groundwater samples, recovery-correction would work well, since the average recoveries of the labeled surrogates in WWTP effluent (185\% for ${ }^{13} \mathrm{C}$-PFOS, $123 \%$ for ${ }^{13} \mathrm{C}_{2}$-PFOA and $105 \%$ for ${ }^{13} \mathrm{C}$-PFDA in QA/QC experiments) and those in groundwater samples $\left(230 \%\right.$ for ${ }^{13} \mathrm{C}$-PFOS, $121 \%$ for ${ }^{13} \mathrm{C}_{2}$-PFOA and $102 \%$ for

${ }^{13} \mathrm{C}$-PFDA) were similar, and the recoveries of most PFAAs and FOSA were within an acceptable range in recovery test using WWTP effluent. Moreover, compared to the wide range of PFAA concentrations in groundwater samples measured $(<0.25-1800 \mathrm{ng} / \mathrm{L})$, the experimental errors would not be a major concern.

\subsection{Source apportionment of PFAAs using PCA-MLR and PFCAR}

We investigated the source contributions to the elevated levels of 55PFAAs (where ' $\Sigma$ PPFAAs' denotes the sum of the respective concentrations of PFOS, PFOA, PFNA, PFDA and PFUnDA) in groundwater, using PCA-MLR and PFCAR. The methods of PCA-MLR and PFCAR are described in S2.1 and S2.2, respectively. Briefly, in PCA-MLR, PFAA 
concentrations were transformed into a dimentionless standardized form (Larsen and Baker,

252 2003; Thurston and Spengler, 1985). PCA was performed using a correlation matrix with a

253 varimax rotation, retaining principal components (PCs) whose eigenvalues were greater than

2541 (Harrison et al., 1996). MLR was done using the PCA factor scores (hereafter, FSs) as

255 independent variables and 55PFAAs as dependent variables. The mean source contributions

256 for all samples were estimated from the ratio of regression coefficients. The source

257 contributions for any given sample were estimated using regression coefficients and its FSs.

258 In PFCAR, two concentration ratios using four PFCAs (PFOA, PFNA, PFDA and PFUnDA)

259 were used: the long/(long + short) ratio $(($ PFDA + PFUnDA $) / \Sigma 4$ PFCAs: L-PFCAR) and the

260 even/(even + odd) ratio $(($ PFOA + PFDA $) / \Sigma 4$ PFCAs: E-PFCAR $)$. These two ratios

261 significantly differ between wastewater and street runoff (Murakami et al., 2009b). The

262 contributions of sewage and street runoff were estimated as follows:

$$
R_{G W}=a \times R_{w w}+b \times R_{S R}
$$

264 where $R_{G W}, R_{W W}$, and $R_{S R}$ are L-PFCAR or E-PFCAR in groundwater in this study, WWTP

265 influent, and street runoff (Murakami et al., 2009b), respectively, and $a$ and $b$ are the

266 contributions (\%) from sewage and street runoff, respectively $(a+b=100 \%)$. We assumed

267 that street runoff was the representative and dominant PFAA source of surface runoff

268 compared with other runoffs (e.g., roof runoff), because PFAA concentrations in street runoff

269 were more than 1 order of magnitude higher than those in rainfall (Murakami et al., 2009a;

270 Murakami et al., 2009b). In order to verify the source apportionment methods above, these

271 methods were also applied to river water, wastewater and street runoff samples reported in

272 and around the study area for a reference (hereafter, 'the reference samples'; S2.3 for details).

\section{3. Results and discussion}




\subsection{Occurrence and concentration of PFAAs in groundwater and tap water}

275 We observed widespread pollution by PFAAs in groundwater (Figure 1 for the spatial 276 distribution; Figure 2 (a) for the detection rate; Figure 2 (b) for the distribution of 277 concentration; Tables S1 for the measured values). PFAAs were detected above the LOQs in $27896 \%$ of the groundwater samples. In these samples, PFHxS, PFOS, PFHpA, PFOA, PFNA 279 and PFDA were the most prevalent, being found in more than $77 \%$ of the samples. Among 280 the PFCAs, those with $\leq 9$ fluorinated carbons (PFHpA, PFOA, PFNA and PFDA) were 281 higher both in detection rate and concentration than those with longer carbon chains 282 (PFUnDA, PFDoDA, PFTrDA and PFTeDA). This would be partly because PFCAs with 283 relatively longer chains are more hydrophobic and likely to be preferentially adsorbed onto 284 solid phases (Higgins and Luthy, 2006; Murakami et al., 2009a). In our previous study, in 285 which artificial street runoff was passed through soil columns, breakthroughs of PFOA, and 286 afterward of PFNA, were observed, while breakthroughs of PFDA and PFUnDA were not 287 clearly observed over 169 days of infiltration (Murakami et al., 2009a). Figure S2 shows the 288 comparison of PFOS, PFOA, PFNA and PFDA levels in the eight groundwater samples 289 investigated both in 2006 (Murakami et al., 2009a) and in 2007 (this study). Compared to the 290 levels of PFOS and PFOA, those of PFNA and PFDA showed greater deviation between in

2912006 and 2007. The good agreement between the respective levels of PFOS and PFOA in the 292 eight groundwater samples the two sampling campaigns would indicate continuous 293 groundwater pollution by those PFAAs, and possibly indicate adsorption equilibrium of both 294 PFOS and PFOA in the subsurface. 


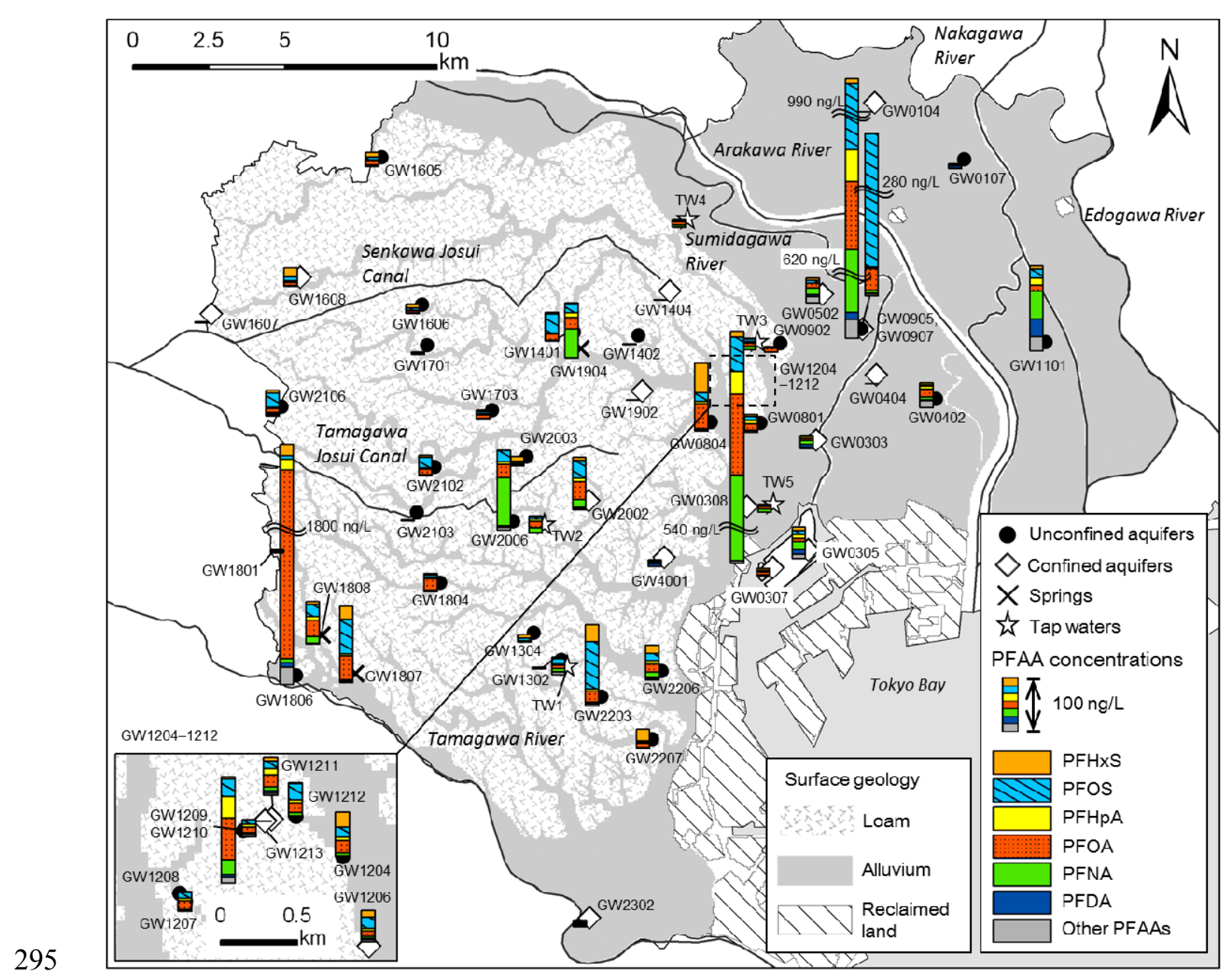

296 Figure 1. Occurrence of PFAAs in groundwater and tap water with surface geology (2001) in

297 Tokyo. (2-column fitting image) 

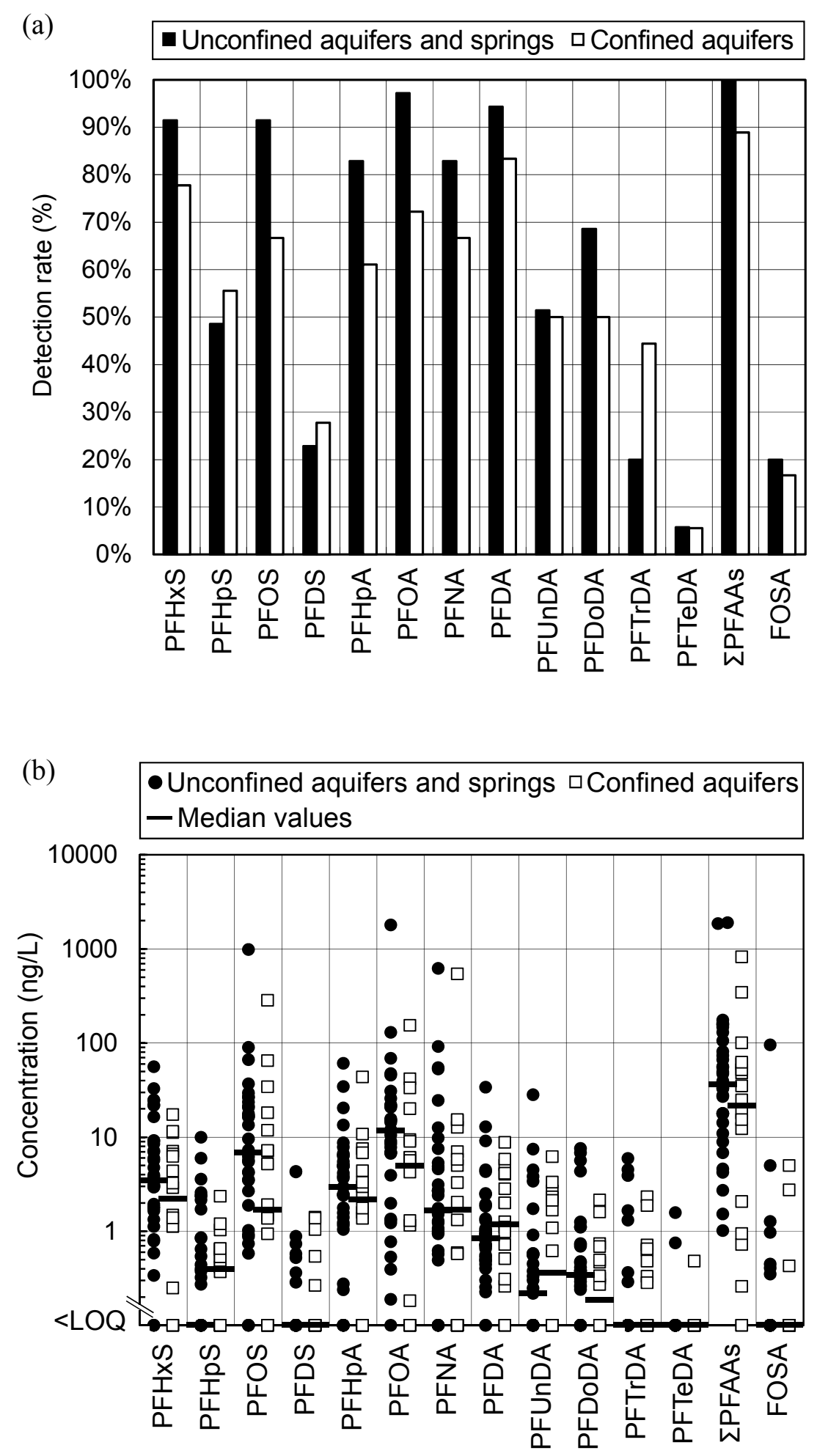

301 Figure 2. The detection rate (a) and concentration (b) of PFAAs and FOSA in groundwater in

302 Tokyo. In (a), the detection rate of $\sum$ PFAAs means the detection rate of any one of PFAAs 
analyzed. (1-column fitting image)

304 Table 1 shows the PFAA concentration ranges in the groundwater and tap water measured in

305 this study, compared with those reported in rivers (Murakami et al., 2008a), wastewater

306 (WWTP influent and secondary effluent) (Murakami et al., 2008a; Murakami et al., 2009b)

307 and street runoff (Murakami et al., 2009b), which represent major environmental media

308 containing appreciable levels of PFAAs in Japan. The median concentration of PFOS in

309 groundwater $(5.7 \mathrm{ng} / \mathrm{L})$ was higher than in Japanese rivers $(0.97 \mathrm{ng} / \mathrm{L}$ (Murakami et al.,

310 2008a)), however that of PFOA was lower in groundwater $(8.5 \mathrm{ng} / \mathrm{L})$ than in rivers $(35 \mathrm{ng} / \mathrm{L})$,

311 partly because of suspected point sources of PFOA (e.g., industries) discharging wastewater

312 into the rivers (Murakami et al., 2008a). For the other PFAAs, the median concentration in

313 groundwater was generally similar to that in rivers. The median concentration of groundwater

314 PFAAs in Tokyo was one order of magnitude lower than that in San Jose, California, and that

315 in New Jersey, where groundwater was impacted by anthropogenic activities (WWTP effluent

316 and PFOA-related facilities, respectively) (Plumlee et al., 2008; Post et al., 2009). The median

317 PFAA levels in Tokyo groundwater were comparable to those in European groundwater

318 (Eschauzier et al., 2010; Loos et al., 2010).

319 While the median PFAA concentrations in groundwater were typically several ng/L, the range

320 in concentration was very large. The maximum concentrations of PFOS (990 ng/L), PFHpA

321 (61 ng/L), PFOA (1800 ng/L), PFNA (620 ng/L) and FOSA (96 ng/L) in groundwater were

322 several times higher than those of wastewater and street runoff (Murakami et al., 2009b) in

323 Tokyo and those of groundwater in the US (Plumlee et al., 2008; Post et al., 2009; Quiñones

324 and Snyder, 2009), Europe (Eschauzier et al., 2010; Loos et al., 2010) and China (Jin et al.,

325 2009). The spatial distribution of PFAAs in groundwater (Figure 1) shows that only a few 
sites, namely, GW0907 (इPFAAs 1900 ng/L), GW1806 (1900 ng/L) and GW0308 (820

327 ng/L), were severely polluted. Their PFAA levels exceeded several international guidelines.

328 Two groundwater samples exceeded the USEPA Provisional Health Advisory value of PFOS

329 (200 ng/L) and a groundwater sample did that of PFOA (400 ng/L). Furthermore, PFOS

330 concentrations in 5 samples exceeded a proposed guideline $(50 \mathrm{ng} / \mathrm{L})$ for the protection of

331 trophic level IV avian species that consume organisms in equilibrium with the water

332 (Rostkowski et al., 2006). Therefore, care should be taken if those groundwaters are directly

333 used for drinking purposes, landscaping or replenishing rivers.

334 While samples from unconfined aquifers and springs were all positive with PFAAs, even

335 confined aquifers had high detection rates (89\%; Figure 2(a)). The median levels of PFAAs

336 from confined aquifer samples were generally only less than one order of magnitude lower

337 than those of unconfined aquifers and springs (Figure 2(b)). The distributions of detection

338 rates and concentrations of PFAAs were very similar among the aquifer types. Moreover,

339 extremely high concentrations of PFOS and PFOA were found in both aquifer types.

340 In tap water, only PFAAs with $\leq 9$ fluorinated carbons (PFHxS, PFOS, PFHpA, PFOA, PFNA

341 and PFDA) and FOSA were detected with concentrations in the order of several ng/L, similar

342 to the median concentrations of these PFAAs in groundwater (Figure 1 for spatial

343 distribution; Table S5 for the measured values). The frequent detection of those PFAAs with

344 relatively short carbon chains in tap water has been reported in several studies (Mak et al.,

345 2009; Quiñones and Snyder, 2009). It has been shown that the treatment methods employed

346 in Tokyo's water supply_flocculation, sedimentation, sand filtration, ozonation and granular

347 activated carbon - are ineffective in removing PFOS and PFOA (Takagi et al., 2011).

\section{3.2. Comparison of PFAA and PPCP levels}


349 In order to investigate the sources and fate of PFAAs in the subsurface, PFAA levels were

350 compared to PPCP levels measured in our parallel study (Kuroda et al., 2012). The

351 groundwater in Tokyo was contaminated by sewage, as confirmed by PPCP detection

352 (Kuroda et al., 2012; Nakada et al., 2008). Figure 3 shows the comparison of PFOS and

353 PFOA levels in aquifers with the levels of two PPCPs (carbamazepine and crotamiton; Table

354 S1) which are known as conservative tracers of sewage (Clara et al., 2004; Nakada et al., 355 2008). The comparison of PFHpA and PFNA and the two PPCPs is shown in Figure S3. In 356 these Figures, the PFAA and PPCP levels in river waters in Japan, and secondary effluents in 357 Tokyo (Murakami et al., 2008a), are also shown. In rivers in Japan, the primary source of 358 PFOS, PFHpA and PFNA was inferred to be secondary effluents (Murakami et al., 2008a).

359 With regard to PFOA, while secondary effluents were suggested as the primary source in 360 most rivers, there was evidence of a significant contribution from point sources other than 361 WWTPs (e.g., industries) to the remarkably high PFOA level in several rivers (Murakami et 362 al., 2008a). 

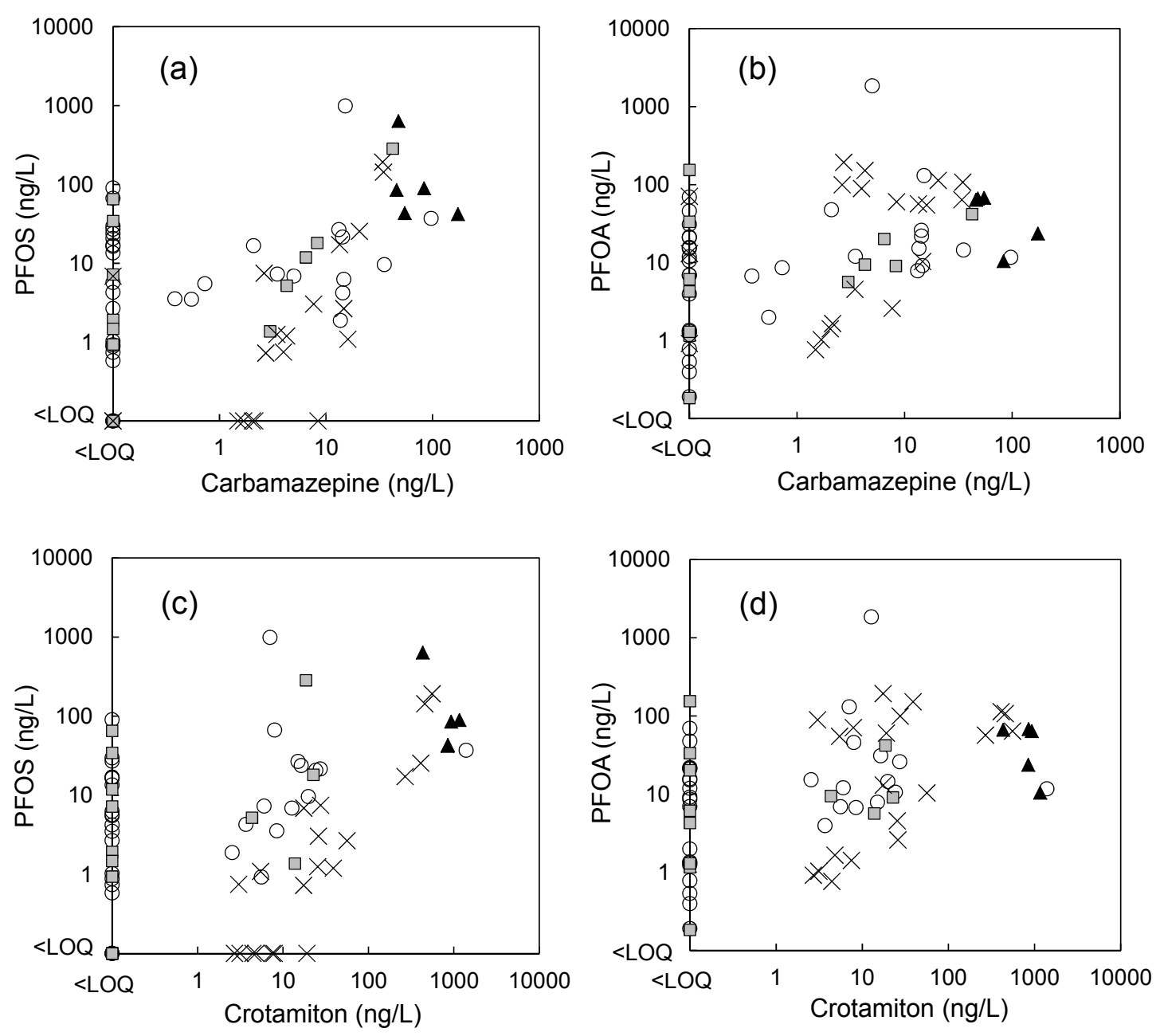

363 O Unconfined aquifers and springs $\square$ Confined aquifers
$\times$ Rivers $\Delta$ Secondary effluents

364 Figure 3. Comparison of PFOS and PFOA with carbamazepine (a, b) and crotamiton (c, d) in

365 groundwater in this study, river waters in Japan (Murakami et al., 2008a), and secondary

366 effluent in Tokyo (Murakami et al., 2008a) in the literature. (2-column fitting image)

367 Sewage was inferred to be a major source of PFAAs in some groundwater samples in which

368 both PFAAs and the sewage-tracer PPCPs were detected, and the groundwater data were

369 distributed around the data points of rivers and secondary effluents. Other groundwater

370 samples, however, showed a different PFAA distribution than was found in samples from 
371 rivers and secondary effluents; the ratio of PFAA to PPCP abundance was greater in the

372 groundwater samples than in the river and secondary effluent samples. Moreover, $30-42 \%$ of

373 the groundwater samples were positive only for PFAAs, while PPCPs were below the LOQs

374 in those samples. There are three possible reasons for the higher abundance and detection

375 rates of PFAAs compared to PPCPs. First, subsurface attenuation of PFAAs may be slower

376 than that of PPCPs. The residence time of confined aquifers of 40-124 $\mathrm{m}$ depth were

377 estimated to be 11-28 years (Imaizumi et al., 2000) and that of unconfined aquifers and

378 springs would be shorter. The half-life of carbamazepine in groundwater is typically $5-10$

379 years (Drewes et al., 2003; Massmann et al., 2008). The half-life of crotamiton has not yet

380 been quantified, although it has been shown to be shorter than that of carbamazepine (Kuroda

381 et al., 2012). On the other hand, PFAAs are the end-products of manufacturing process of

382 perfluoroalkyl and polyfluoroalkyl substances, and thereby highly recalcitrant to

383 biodegradation, owing to their very strong carbon-fluorine bonds. Therefore, higher

384 PFAA/PPCP ratios with crotamiton than that with carbamazepine found in samples with high

385 levels of PFAAs might be attributed to the lesser half-life of crotamiton. Second, detection of

386 PFAAs at appreciable levels, despite the absence of PPCPs, may indicate the contribution of

387 other sources than sewage (e.g., surface runoff and point sources) to groundwater PFAAs.

388 Third, PFAAs might be formed from precursors while passing through soils. Formation of

389 PFAAs from precursors under biologically active conditions was indicated in the activated

390 sludge process (Guerra et al., 2014; Schultz et al., 2006; Sinclair and Kannan, 2006) and in

391 soil-water systems (Murakami et al., 2013; Murakami et al, 2008b). It has been shown that

392 urban runoff also contained PFAA precursors in a significant amount (Houtz and Sedlak,

393 2012). In the present study, FOSA was detected at only $19 \%$ of groundwater samples and it 
394 was detected in samples with high levels of PFOS and PFOA (Figure S4).

395 Adsorption to soils may have a minor effect on subsurface attenuation of the four PFAAs

396 (PFOS, PFHpA, PFOA and PFNA) and the two PPCPs. Similar to PFOS and PFOA, the

397 concentrations of the two PPCPs in Tokyo groundwater were unchanged between in 2006 and

3982007 (Kuroda et al., 2012). Therefore, during the long-term continuous pollution of

399 groundwater, adsorption equilibrium on the subsoil would have been reached for PFOS,

400 PFOA, carbamazepine, crotamiton and perhaps PFHpA, whose carbon chain is shorter than

401 PFOA. In our previous soil column percolation experiments using secondary effluents, 402 breakthroughs of the two PPCPs were observed (Shinohara et al., 2006). Adsorption on soil

403 might have influenced the attenuation of PFNA, especially in the samples that had lower

404 PFNA/carbamazepine ratios than those of rivers and secondary effluent. For PFAAs whose

405 carbon-chains are longer than PFNA, adsorption to soils would have been a major issue, as

406 stated in section 3.1 and Figure 2. Temporal changes in PFAA and PPCP consumption would

407 not have influenced greatly to the relative abundance of PFAAs in groundwater, which should

408 be older than the PFAAs in rivers and secondary effluents. While annual PFAA consumption

409 data are not available, the time-trend of PFAA usage in Tokyo may be estimated from PFAA

410 levels in Tokyo Bay sediments (Zushi et al., 2010). Between 1990 and 2004, the ratio of

411 PFAA concentrations in Tokyo Bay sediments to carbamazepine consumption (Ministry of

412 Health, 1990-2004) did not change significantly (Figure S5).

413 Based on the observed PFAA levels ( several ng/L) in tap water, leakage from water mains

414 may provide the background levels, but would not account for the elevated levels of PFAAs

415 in groundwater. However, surface runoff may be a source of elevated PFAAs in groundwater,

416 along with sewage. In Japan, street runoff and storm water runoff contain high levels of 
417 PFAAs (e.g., maximum PFNA 172 ng/L; Table 1), causing non-point PFAA pollution in

418 urban surface waters (Murakami et al., 2009b; Nishikoori et al., 2011; Zushi and Masunaga,

419 2009; Zushi et al., 2008). PFAA concentrations in rainwater in Tokyo area were only at low

420 ng/L levels (Kwok et al., 2010; Murakami et al., 2009b; Nishikoori et al., 2011).

421 Regarding point sources, only GW1806, with a remarkably high PFOA concentration (1800

$422 \mathrm{ng} / \mathrm{L}$ ), was possibly polluted by point sources; in this case, sources such as industrial

423 facilities. There was a storage space for industrial wastes within $100 \mathrm{~m}$ away from the well,

424 but its usage of fluorochemicals was not known. In several rivers in Japan, where point 425 sources other than WWTPs (e.g., industries) have been suggested as the major sources of 426 PFOA (Murakami et al., 2008a), distinctively PFOA-dominated PFAA compositions have 427 been reported (PFOA/PFOS: 13-703; PFOA/PFNA: 28-163; and \%PFOA (PFOA/(PFOA, 428 PFNA, PFDA and PFUnDA)): 90-99\%). Such compositions were not found in other rivers $429(0.33-16,0.7-6.2,35-78 \%)$, in wastewater $(0.08-2.9,0.4-1.4,26-55 \%)$, or in street runoff 430 (1.8-16, 2.0-7.4, 44-65\%), in Japan (Murakami et al., 2008a; Murakami et al., 2009b). In 431 groundwater, only GW1806 had such a PFOA-dominated composition $(269,244,99 \%)$. In 432 tributaries of the Rhine River, contaminated organic waste applied in agricultural areas was a 433 suspected source of specifically elevated PFOA (Skutlarek, 2006). In Tokyo, however, 434 biosolids are unlikely sources of PFAAs because agricultural land is located only in 435 peripheral areas, and biosolids application is not a common practice.

\section{3.3. Source apportionment of PFAAs in groundwater}

437 In PCA-MLR using 5PFAAs (PFOS, PFOA, PFNA, PFDA and PFUnDA) in 53 groundwater 438 samples as input data, 3 PCs were obtained. Table S6 shows the rotated component matrix 439 and loadings after rotation. On the basis of the PFAA profiles observed in Japan and 
440 comparison with the reference samples, PCs 1-3 were interred to be sewage, street runoff and

441 point sources, respectively (S2.1). Figures 4 (a) and (b) show the FSs and source contributions

442 of PCs resulted from PCA-MLR, for the 10 groundwater samples which had the highest

443 55PFAAs, respectively. On the basis of regression coefficients from MLR, the mean percent

444 contribution to 55PFAAs was $44.6 \%$ sewage, $9.7 \%$ street runoff and $45.7 \%$ point sources.

445 When input data for PCA was changed (i.g., 5PFAAs and carbamazepine as input variables;

446 groundwater samples and the reference samples as input samples), the FS distribution and

447 source contributions of the 10 groundwater samples did not change greatly (S3).

448 In PFCAR, both L-PFCAR and E-PFCAR gave consisitent estimates of sewage-street runoff

449 source apportionment in four groundwater samples, including those from the two most 450 contaminated sites (GW0907 and GW0308), where sewage was the principal source of

451 pollution (Figures $4(\mathrm{c})$ and $4(\mathrm{~d})$ ). Those results were very similar to PCA-MLR results, when

452 PC3 was regarded as a member of sewage group. On the other hand, in the 6 groundwater

453 samples with lesser 5 5PFAAs, the E-PFCAR results were different from the results of the

454 other two methods; namely, in 5 out of the 6, L-PFCAR indicated sewage as the principal

455 source. In our previous soil column percolation experiments, the effluents showed a lesser

456 L-PFCAR result, and a greater E-PFCAR result, in comparison with the influents, owing to

457 the preferential partitioning of PFDA and PFUnDA over PFOA and PFNA during soil

458 passage (Murakami et al., 2009a). Therefore, L-PFCAR may overestimate, and E-PFCAR

459 may underestimate the contribution of sewage to 5 5PFAAs in groundwater (Murakami et al.,

460 2009a). Meanwhile, L-PFCAR gave reasonable source estimation for the reference samples

461 (Figure S9). Moreover, L-PFCAR and PCA-MLR gave consistent results. It was therefore

462 indicated that PCA-MLR and L-PFCAR were more viable than E-PFCAR in source 
463 apportionment of $\Sigma 5$ PFAAs in groundwater. With L-PFCAR, the respective fractions of

$464 \quad$ 55PFAAs attributed to sewage and street runoff were $82 \%$ and $18 \%$ of the sum of $\Sigma 5$ PFAAs

465 in the 10 groundwater samples.

466 To further validate the above-mentioned source apportionment methods, the source

467 apportionment results were compared with concentrations of carbamazepine (Kuroda et al.,

468 2012) and heavy metals (Kuroda, 2010) measured in the same samples, using Spearman's

469 rank-order correlation analysis (Table S8). The heavy metals, $\mathrm{Cd}, \mathrm{Co}, \mathrm{Cr}, \mathrm{Cu}, \mathrm{Ni}$ and $\mathrm{Zn}$,

470 were contained in urban runoff at high concentrations (Han et al., 2006; Joshi and

471 Balasubramanian, 2010). The results showed that PCA-MLR and L-PFCAR are viable

472 methods for estimating the contribution of sewage and street runoff in groundwater. The

473 original 55PFAAs before source-apportionment positively correlated with carbamazepine, $\mathrm{Ni}$

474 and Zn. PCA-MLR and L-PFCAR results, however, gave a more reasonable correspondence

475 with carbamazepine and heavy metals. PC1, PC3 and the $\Sigma 5$ PFAAs fractions attributed to

476 sewage by L-PFCAR had positive correlations with only carbamazepine. On the other hand,

477 PC2 and the street runoff-attributed 55PFAAs fractions by L-PFCAR correlated with several

478 heavy metals. Furthermore, the sum of PC1 and PC3 turned out to have a stronger correlation

479 with carbamazepine than PC1 or PC3 alone; this would be because multiple PPCPs were

480 detected at relatively high concentrations in point source-suspected GW1806 (Kuroda et al.,

481 2012). This could also suggest a close relationship between point source-derived PFAAs and

482 sewage. On the other hand, the source-attributed 5 5PFAAs fractions estimated by E-PFCAR

483 did not have reasonable correlations with carbamazepine or heavy metals. E-PFCAR was

484 possibly not an appropriate source apportionment method, due to the greater error resulting

485 from the difference in E-PFCAR, relating street runoff and WWTP influent (street 
runoff/WWTP influent $=0.72 / 0.45=1.6$ times), being smaller than that in L-PFCAR

$487(0.26 / 0.03=8.7$ times $)$. At stations GW0907 and GW1101, the larger fraction of sewage-attributed 55PFAAs estimated by E-PFCAR could be attributed to this small dynamic range of E-PFCAR.

To wrap up, both PCA-MLR and L-PFCAR were viable methods for sewage-street runoff source apportionment. Moreover, PCA-MLR enabled estimation of point source-derived PFAAs. Both methods suggested sewage and point sources as the dominant sources of ¿5PFAAs in severely contaminated groundwater, with street runoff being a relatively minor source.

495
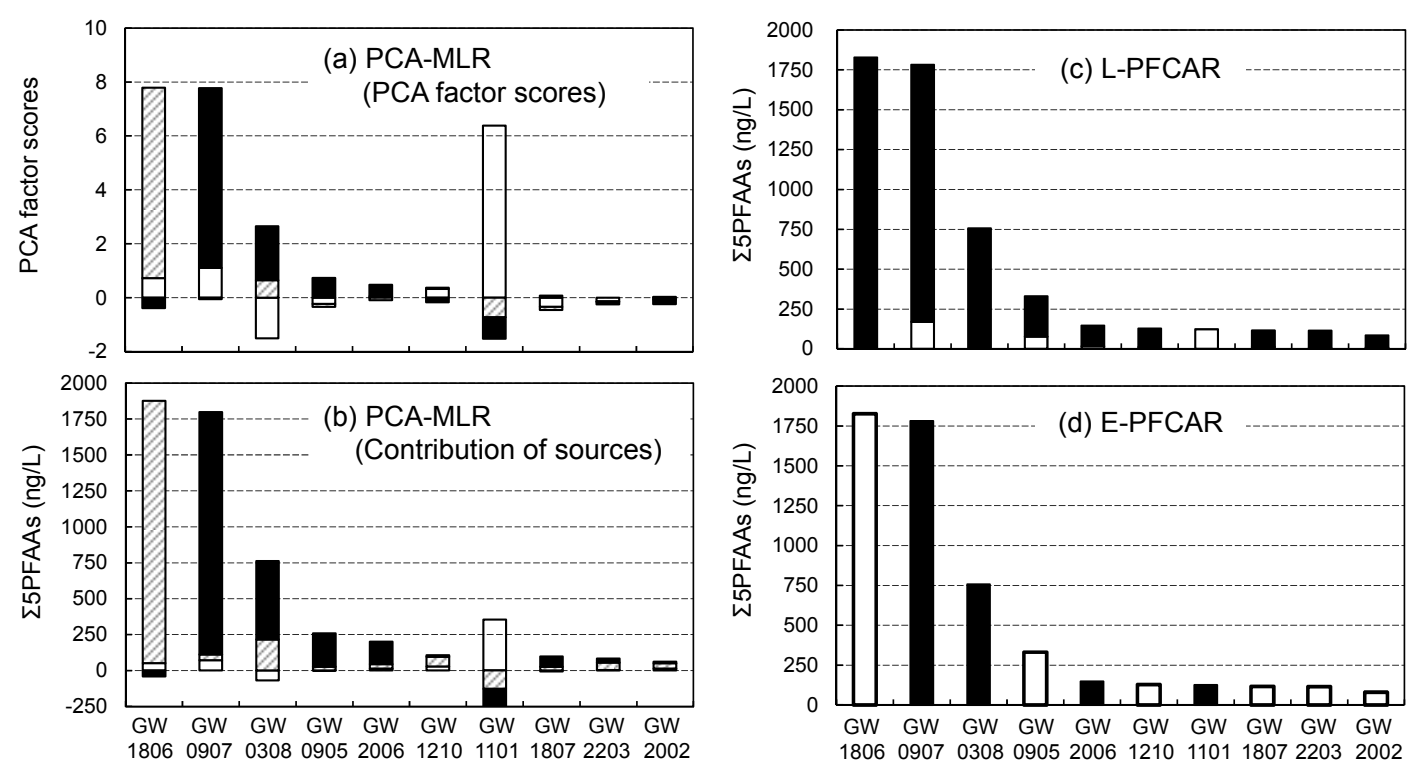

$\square \mathrm{PC} 1 \quad \square \mathrm{PC} 2 \quad \mathrm{QPC} 3$

497 Figure 4. Source apportinment of 10 groundwater samples with the highest $\Sigma 5$ PFCAs by

498 PCA-MLR (a: factor scores; b: contribution of sources), L-PFCAR (c) and E-PFCAR (d).

499 (2-column fitting image) 


\subsection{Pathways of PFAAs in aquifers, based on tritium analysis}

502 Tritium is a radioactive isotope of hydrogen, with a half-life of 12.33 years (Lucas and

503 Unterweger, 2000), and is useful in differentiating young groundwater, recharged after the

504 1950s and 1960s, from old groundwater (see Figure S9).

505 In Figure 5, 5 PFAAs was compared with well depths and tritium indicators (concentration 506 data in Table S9). Tritium samples at $<50 \mathrm{~m}$ depth had concentrations of 1.7-4.2 TU, which 507 suggested that the samples contained young groundwater likely recharged during or after the 508 1970s (see Figure S9). PFAAs were detected in all these samples, and at high concentrations 509 in some. Since PFAAs had already been in widespread use before the recharge of the aquifers,

510 the water may have been polluted before or shortly after recharge near the ground surface

511 (e.g., by atmospheric sources, infiltration of surface runoff, or sewer exfiltration). As

512 discussed above, the pollution sources of the groundwater samples with very high maximum

513 PFAA levels were associated with sewage. As was the case with PPCPs (Kuroda et al., 2012),

514 the large variation in the observed PFAA concentrations could be explained by 515 locally-occurring pollution mechanisms, such as sewer exfiltration, and by the large variation 516 in PFAA source levels and the degree of dilution.

517 The other two tritium analysis samples (GW1213: $130 \mathrm{~m}$ depth; and GW4001: $500 \mathrm{~m}$ depth)

518 both contained old groundwater ( $0.4 \mathrm{TU}$ and $<0.3 \mathrm{TU}$, respectively), which had been 519 recharged before the 1950s. Therefore, it was not surprising that no PFAAs were detected at 520 GW1213, because PFAAs were not yet in use when the groundwater was recharged. 521 However, PFAAs were detected at GW4001. In addition, caffeine, a labile marker of sewage 522 (Buerge et al., 2003), was detected, at $11 \mathrm{ng} / \mathrm{L}$, in this sample (Kuroda et al., 2012). Since it is 523 highly unlikely that the caffeine had persisted for more than 50 years, it is likely that 
524 GW4001, and perhaps other PFAA-positive deep groundwater samples, were contaminated 525 due to defects in well casings, which would allow contamination by young groundwater from 526 the upper aquifers.

527

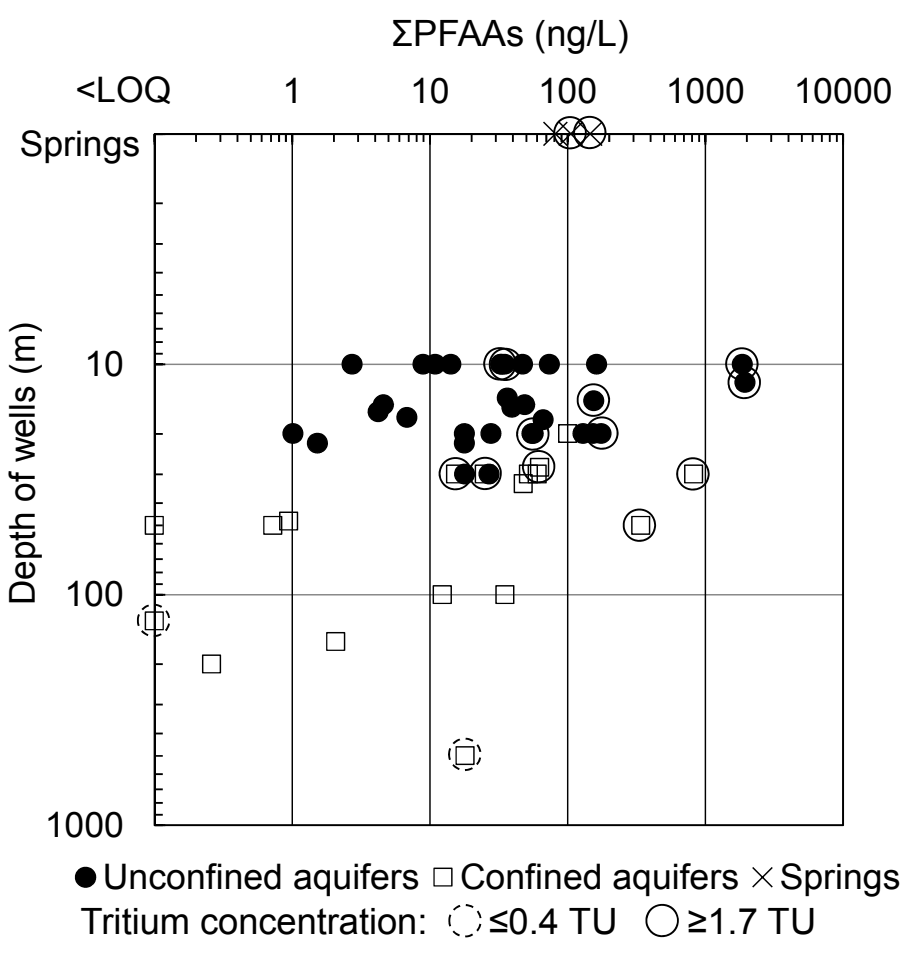

528

Figure 5. PPFAAs with depth of wells and concentration of tritium. (1-column fitting image)

3.5. PPCP analysis, tritium analysis, PCA-MLR and L-PFCAR as means of evaluating groundwater pollution by PFAAs

533 This study demonstrated the utility of PPCP analysis, tritium analysis, PCA-MLR, PFCAR, 534 and their combined use in investigating the sources and pathways of PFAA pollution in 535 multiple aquifer systems. PPCPs served as indicators of pollution by sewage in individual 536 groundwater samples. Moreover, they were useful in obtaining a general idea of the sources 537 of, and processes involving, PFAAs in groundwater, and in validating source apportionment 
538 methods. Quantitative source assessment of individual samples, however, would be difficult 539 using PPCPs alone in the study site, because the relationship between PPCPs and 540 sewage-attributed PFAAs was not linear, because of several factors involving the relationship 541 between PPCPs and PFAAs in groundwater (section 3.2); the correlation between 542 concentrations of PPCPs and sewage-attributed 55PFAAs was significant but not strong 543 enough (maximum $\rho=0.64$ : Table S8) for such quantitative assessment. Moreover, PPCP 544 concentrations were below the LOQs in GW0308, which was considered to be severely 545 polluted by sewage. In contrast, in a site where WWTP effluent was recharged into an aquifer 546 through a lagoon, carbamazepine was shown to be an effective quantitative tracer of sewage 547 within a residence time of two years (Gasser et al., 2010). This contrast would be partly 548 owing to attenuation of PPCPs over the (presumably) longer residence times involved in the 549 present study, and partly to random mixing of PFAAs and PPCPs in the Tokyo sewers. For 550 source assessment of individual groundwater samples, PCA-MLR and L-PFCAR are viable 551 methods. In this study, while both methods enabled source apportionment between sewage 552 and street runoff, PCA-MLR was useful in distinguishing point source-derived PFAAs with 553 anomalous PFAA compositions. Both methods require PFAA profiles of potential PFAA 554 sources, which might vary among countries and regions. Tritium analysis was useful in 555 distinguishing old groundwater that theoretically does not contain PFAAs. Therefore, the 556 pollution mechanisms involving young groundwater (e.g., sewer exfiltration, infiltration of 557 street runoff) and old groundwater (e.g., defects of well structure) were indicated by a 558 combined use of tritium and PPCP analyses.

559 More generally, since groundwater is characterized by a long residence time, countermeasures 560 and regulatory actions against PFAA pollution, such as PFAA-use reduction, production 
561 phaseout and short-chain PFAA shift, may eventually achieve low PFAA levels in

562 groundwater. Meanwhile, PFAA levels in deep aquifers may increase due to the legacy of

563 past PFAA use, production from precursors, or contamination by young groundwater.

564 Therefore, continuous monitoring of PFAAs in aquifers, using the above-mentioned tracers

565 and source apportionment methods, would seem essential work for the future.

\section{4. Conclusions}

567 The ubiquitous occurrence of PFAAs in samples from all types of aquifers, at almost all

568 depths, showed the high vulnerability of Tokyo's aquifers to pollution by PFAAs. While 569 PFAAs' median concentrations were low (several ng/L), a few of groundwater samples had 570 high levels of PFAAs (up to $1800 \mathrm{ng} / \mathrm{L}$ ). PFAAs were more frequently detected than 571 sewage-tracer PPCPs, carbamazepine and crotamiton. Sources of severe PFAA pollution were 572 inferred as sewage and point sources by using PCA-MLR and L-PFCAR. A combined use of 573 tritium and PPCPs indicated the pollution mechanism of both shallow young groundwater 574 recharged after 1950s (sewer exfiltration, infiltration of street runoff) and deep old 575 groundwater recharged before 1950s (detects of well structure). Overall, PPCP analysis, 576 tritium analysis, PCA-MLR and L-PFCAR were shown to be useful in investigating sources 577 and pathways of multi-sourced PFAAs in multiple aquifer systems.

\section{Acknowledgments}

579 The authors thank the members of Laboratory of Urban Water Systems, the University of 580 Tokyo, the members of Laboratory of Organic Geochemistry, Tokyo University of 581 Agriculture and Technology, and the local government officers for their help in sample 582 collection and analysis. This study was supported in part by Grant-in-aid for Scientific 583 Research (\#22404012) and Research Fellowships for Young Scientists (\#21-04295) from 
584 Japan Society for the Promotion of Science, and a CREST project grant for 'Development of 585 Well-balanced Urban Water Use System Adapted for Climate Change' from the Japan 586 Science and Technology Agency.

587 
604

605

606

607

608

609

610

611

612

613

614

615

616

617

618

619

620

621

622

623

624

625

626

627

628

629

630

631

632

633

634

635

636

637

\section{REFERENCES}

Buck RC, Franklin J, Berger U, Conder JM, Cousins IT, de Voogt P, et al. Perfluoroalkyl and polyfluoroalkyl substances in the environment: Terminology, classification, and origins. Integrated Environ. Assess. Manag. 2011; 7: 513-541.

Buerge IJ, Poiger T, Müller MD, Buser H-R. Caffeine, an anthropogenic marker for wastewater contamination of surface waters. Environ. Sci. Technol. 2003; 37: 691-700.

Bureau of Urban Development, Tokyo Metropolitan Government (Website in Japanese); http://www.toshiseibi.metro.tokyo.jp/

Bureau of Waterworks, Tokyo Metropolitan Government (Website in Japanese); http://www.waterprofessionals.metro.tokyo.jp/index.html

Clara M, Strenn B, Kreuzinger N. Carbamazepine as a possible anthropogenic marker in the aquatic environment: investigations on the behavior of carbamazepine in wastewater treatment and during groundwater infiltration. Water Res. 2004; 38: 947-954.

Conder JM, Hoke RA, Wolf Wd, Russell MH, Buck RC. Are PFCAs bioaccumulative? A critical review and comparison with regulatory criteria and persistent lipophilic compounds. Environ. Sci. Technol. 2008; 42: 995-1003.

Drewes JE, Heberer T, Rauch T, Reddersen K. Fate of pharmaceuticals during ground water recharge. Ground Water Monit. Rem. 2003; 23: 64-72.

Endo T. Confined groundwater system in Tokyo. Environ. Geol. Water Sci. 1992; 20: 21-34.

Eschauzier C, Haftka J, Stuyfzand PJ, de Voogt P. Perfluorinated compounds in infiltrated River Rhine water and infiltrated rainwater in coastal dunes. Environ. Sci. Technol. 2010; 44: 7450-7455.

Furl CV, Meredith CA, Strynar MJ, Nakayama SF. Relative importance of wastewater treatment plants and non-point sources of perfluorinated compounds to Washington State rivers. Sci. Total Environ. 2011; 409: 2902-2907.

Gasser G, Rona M, Voloshenko A, Shelkov R, Tal N, Pankratov I, et al. Quantitative evaluation of tracers for quantification of wastewater contamination of potable water sources. Environ. Sci. Technol. 2010; 44: 3919-3925.

Guerra P, Kim M, Kinsman L, Ng T, Alaee M, Smyth SA. Parameters affecting the formation of perfluoroalkyl acids during wastewater treatment. J. Hazard. Mater. 2014; 272: $148-154$.

Han YH, Lau SL, Kayhanian M, Stenstrom MK. Correlation analysis among highway stormwater pollutants and characteristics. Water Sci. Technol. 2006; 53: 235-243.

Harrison RM, Smith DJT, Luhana L. Source apportionment of atmospheric polycyclic aromatic hydrocarbons collected from an urban location in Birmingham, U.K. Environ. Sci. Technol. 1996; 30: 825-832.

Higgins CP, Field JA, Criddle CS, Luthy RG. Quantitative determination of perfluorochemicals in sediments and domestic sludge. Environ. Sci. Technol. 2005; 39: 3946-3956.

Higgins CP, Luthy RG. Sorption of perfluorinated surfactants on sediments. Environ. Sci. Technol. 2006; 40: 7251-7256.

Houtz EF, Higgins CP, Field JA, Sedlak DL. Persistence of perfluoroalkyl acid precursors in AFFF-impacted groundwater and soil. Environ. Sci. Technol. 2013; 47: 8187-8195.

Houtz EF, Sedlak DL. Oxidative conversion as a means of detecting precursors to perfluoroalkyl acids in urban runoff. Environ. Sci. Technol. 2012; 46: 9342-9349.

Huset CA, Chiaia AC, Barofsky DF, Jonkers N, Kohler H-PE, Ort C, et al. Occurrence and mass flows of fluorochemicals in the Glatt Valley watershed, Switzerland. Environ. Sci. Technol. 2008; 42: 6369-6377. 
660

661

662

663

664

665

666

667

668

669

670

671

672

673

674

675

676

677

678

679

680

681

682

683

684

685

686

687

Imaizumi M, Komae T, Nihira S. Evaluation of recharge mechanism of confined groundwater using long term tritium concentration records in the metropolis of Tokyo. J. Japan Soc. Eng. Geol. (in Japanese with English abstract) 2000; 41: 87-102.

Jin YH, Liu W, Sato I, Nakayama SF, Sasaki K, Saito N, et al. PFOS and PFOA in environmental and tap water in China. Chemosphere 2009; 77: 605-611.

Joshi UM, Balasubramanian R. Characteristics and environmental mobility of trace elements in urban runoff. Chemosphere 2010; 80: 310-318.

Kim S-K, Kannan K. Perfluorinated acids in air, rain, snow, surface runoff, and lakes: relative importance of pathways to contamination of urban lakes. Environ. Sci. Technol. 2007; 41: 8328-8334.

Kissa E. Fluorinated Surfactants and Repellants, 2nd ed.; Marcel Dekker Inc.: New York, 2001.

Kuroda K. Evaluation of potential of groundwater for the improvement of urban environments. dissertation, The University of Tokyo, 2010.

Kuroda K, Murakami M, Oguma K, Muramatsu Y, Takada H, Takizawa S. Assessment of groundwater pollution in Tokyo using PPCPs as sewage markers. Environ. Sci. Technol. 2012; 46: 1455-1464.

Kwok KY, Taniyasu S, Yeung LWY, Murphy MB, Lam PKS, Horii Y, et al. Flux of perfluorinated chemicals through wet deposition in Japan, the United States, and several other countries. Environ. Sci. Technol. 2010; 44: 7043-7049.

Larsen RK, Baker JE. Source apportionment of polycyclic aromatic hydrocarbons in the urban atmosphere: a comparison of three methods. Environ. Sci. Technol. 2003; 37: 1873-1881.

Loos R, Locoro G, Comero S, Contini S, Schwesig D, Werres F, et al. Pan-European survey on the occurrence of selected polar organic persistent pollutants in ground water. Water Res. 2010; 44: 4115-4126.

Lucas L, L., Unterweger M, P. Comprehensive review and critical evaluation of the half-fife of tritium. J. Res. Natl. Inst. Stand. Technol. 2000; 105: 541-549.

Mak YL, Taniyasu S, Yeung LWY, Lu G, Jin L, Yang Y, et al. Perfluorinated compounds in tap water from China and several other countries. Environ. Sci. Technol. 2009; 43: 4824-4829.

Massmann G, Sultenfuss J, Dunnbier U, Knappe A, Taute T, Pekdeger A. Investigation of groundwater a residence times during bank filtration in Berlin: multi-tracer approach. Hydrol. Processes 2008; 22: 788-801.

Ministry of Health, Labour and Welfare of Japan. The statistical yearbook of pharmaceutical industry productions trends, 1990-2004. (in Japanese)

Moody CA, Field JA. Determination of perfluorocarboxylates in groundwater impacted by fire-fighting activity. Environ. Sci. Technol. 1999; 33: 2800-2806.

Morimoto T, Muramatsu Y, Takeshita A, Shimizu A, Murakami M, Takada H. Concentrations of water-soluble organic micropollutants and anthropogenic molecular markers in influent and effluent from sewage treatment plant. J. Water Waste (in Japanese with English abstract) 2011; 53: 635-646.

Murakami M, Imamura E, Shinohara H, Kiri K, Muramatsu Y, Harada A, et al. Occurrence and sources of perfluorinated surfactants in rivers in Japan. Environ. Sci. Technol. 2008a; 42: 6566-6572.

Murakami M, Kuroda K, Sato N, Fukushi T, Takizawa S, Takada H. Groundwater pollution by perfluorinated surfactants in Tokyo. Environ. Sci. Technol. 2009a; 43: 3480-3486.

Murakami M, Morita C, Morimoto T, Takada H. Source analysis of perfluorocarboxylates in Tokyo Bay during dry weather and wet weather using sewage markers. Environ. Chem. 2011; 8: 355-362. 
Murakami M, Nishikoori H, Sakai H, Oguma K, Takada H, Takizawa S. Formation of perfluorinated surfactants from precursors by indigenous microorganisms in groundwater. Chemosphere 2013; 93: 140-145.

Murakami M, Sato N, Anegawa A, Nakada N, Harada A, Komatsu T, et al. Multiple evaluations of the removal of pollutants in road runoff by soil infiltration. Water Res. 2008b; 42: 2745-2755.

Murakami M, Shinohara H, Takada H. Evaluation of wastewater and street runoff as sources of perfluorinated surfactants (PFSs). Chemosphere 2009b; 74: 487-493.

Nakada N, Kiri K, Shinohara H, Harada A, Kuroda K, Takizawa S, et al. Evaluation of pharmaceuticals and personal care products as water-soluble molecular markers of sewage. Environ. Sci. Technol. 2008; 42: 6347-6353.

Nakayama SF, Strynar MJ, Reiner JL, Delinsky AD, Lindstrom AB. Determination of perfluorinated compounds in the upper Mississippi River basin. Environ. Sci. Technol. 2010; 44: 4103-4109.

Nguyen VT, Reinhard M, Karina GY-H. Occurrence and source characterization of perfluorochemicals in an urban watershed. Chemosphere 2011; 82: 1277-1285.

Nishikoori H, Murakami M, Sakai H, Oguma K, Takada H, Takizawa S. Estimation of contribution from non-point sources to perfluorinated surfactants in a river by using boron as a wastewater tracer. Chemosphere 2011; 84: 1125-1132.

OECD, OECD portal on perfluorinated chemicals, 2011;

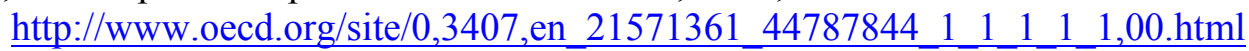

Olsen GW, Chang S-C, Noker PE, Gorman GS, Ehresman DJ, Lieder PH, et al. A comparison of the pharmacokinetics of perfluorobutanesulfonate (PFBS) in rats, monkeys, and humans. Toxicology 2009; 256: 65-74.

Plumlee MH, Larabee J, Reinhard M. Perfluorochemicals in water reuse. Chemosphere 2008; 72: $1541-1547$.

Post GB, Louis JB, Cooper KR, Boros-Russo BJ, Lippincott RL. Occurrence and potential significance of perfluorooctanoic acid (PFOA) detected in New Jersey public drinking water systems. Environ. Sci. Technol. 2009; 43: 4547-4554.

Prevedouros K, Cousins IT, Buck RC, Korzeniowski SH. Sources, fate and transport of perfluorocarboxylates. Environ. Sci. Technol. 2005; 40: 32-44.

Quiñones O, Snyder SA. Occurrence of perfluoroalkyl carboxylates and sulfonates in drinking water utilities and related waters from the United States. Environ. Sci. Technol. 2009; 43: 9089-9095.

Rostkowski P, Yamashita N, So IMK, Taniyasu S, Lam PKS, Falandysz J, et al. Perfluorinated compounds in streams of the Shihwa industrial zone and Lake Shihwa, South Korea. Environ. Toxicol. Chem. 2006; 25: 2374-2380.

Sakurai T, Serizawa S, Isobe T, Kobayashi J, Kodama K, Kume G, et al. Spatial, phase, and temporal distributions of perfluorooctane sulfonate (PFOS) and perfluorooctanoate (PFOA) in Tokyo Bay, Japan. Environ. Sci. Technol. 2010; 44: 4110-4115.

Schultz MM, Barofsky DF, Field JA. Quantitative determination of fluorotelomer sulfonates in groundwater by LC MS/MS. Environ. Sci. Technol. 2004; 38: 1828-1835.

Schultz MM, Higgins CP, Huset CA, Luthy RG, Barofsky DF, Field JA. Fluorochemical mass flows in a municipal wastewater treatment facility. Environ. Sci. Technol. 2006; 40: 7350-7357.

Scott BF, Spencer C, Mabury SA, Muir DCG. Poly and perfluorinated carboxylates in North American precipitation. Environ. Sci. Technol. 2006; 40: 7167-7174.

Shinohara H, Murakami M, Managaki S, Kojima S, Takada H, Sato N, et al. Removal of water-soluble organicmicro-pollutants by soil infiltration. J. Environ. Sci. (in Japanese with English abstract and figure captions) 2006; 19,: 435-444. 
Simcik MF, Dorweiler KJ. Ratio of perfluorochemical concentrations as a tracer of atmospheric deposition to surface waters. Environ. Sci. Technol. 2005; 39: 8678-8683.

Sinclair E, Kannan K. Mass loading and fate of perfluoroalkyl surfactants in wastewater treatment plants. Environ. Sci. Technol. 2006; 40: 1408-1414.

Skutlarek DE, M.; Färber, H. . Perfluorinated surfactants in surface and drinking waters. Environ. Sci. Pollut. Res. 2006; 13: 299-307.

Takagi S, Adachi F, Miyano K, Koizumi Y, Tanaka H, Watanabe I, et al. Fate of perfluorooctanesulfonate and perfluorooctanoate in drinking water treatment processes. Water Res. 2011; 45: 3925-3932.

Thurston GD, Spengler JD. A quantitative assessment of source contributions to inhalable particulate matter pollution in metropolitan Boston. Atmos. Environ. 1985; 19: 9-25.

Tokyo Institute of Civil Engineering and Technology Research, Geological map of Tokyo. In Geology of Tokyo (1), 1977 (in Japanese).

Tokyo Institute of Civil Engineering and Technology Research, Map of deep underground of Tokyo. In Geological Map of Tokyo (6), 1996 (in Japanese).

Tokyo Metropolitan Government. Basic survey of land, 2001 (in Japanese).

Tokyo Metropolitan Government. Report on land subsidence and groundwater in Tokyo, 2006 (Website in Japanese); http://www.kankyo.metro.tokyo.jp/water/groundwater/index.html

USEPA, Long-chain perfluorinated chemicals (PFCs) action plan, Washington DC, 2009; http://www.epa.gov/opptintr/existingchemicals/pubs/pfes_action_plan1230_09.pdf.

Watanabe H, Murakami M, Komura T, Moroizumi T, Furumai H. Evaluation of water balance and water use stress in principal cities in Japan. J. Water Waste (in Japanese with English abstract) 2009; 51: 137-148.

Weiß O, Wiesmüller GA, Bunte A, Göen T, Schmidt CK, Wilhelm M, et al. Perfluorinated compounds in the vicinity of a fire training area - human biomonitoring among 10 persons drinking water from contaminated private wells in Cologne, Germany. Int. J. Hyg. Environ. Health 2012; 215: 212-215.

Xiao F, Simcik MF, Gulliver JS. Perfluoroalkyl acids in urban stormwater runoff: Influence of land use. Water Res. 2012; 46: 6601-6608.

Zushi Y, Masunaga S. First-flush loads of perfluorinated compounds in stormwater runoff from Hayabuchi River basin, Japan served by separated sewerage system. Chemosphere 2009; 76: 833-840.

Zushi Y, Takeda T, Masunaga S. Existence of nonpoint source of perfluorinated compounds and their loads in the Tsurumi River basin, Japan. Chemosphere 2008; 71: 1566-1573.

Zushi Y, Tamada M, Kanai Y, Masunaga S. Time trends of perfluorinated compounds from the sediment core of Tokyo Bay, Japan (1950s-2004). Environ. Pollut. 2010; 158: 756-763.

Zushi Y, Ye F, Motegi M, Nojiri K, Hosono S, Suzuki T, et al. Spatially detailed survey on pollution by multiple perfluorinated compounds in the Tokyo Bay basin of Japan. Environ. Sci. Technol. 2011; 45: 2887-2893. 